\title{
Intracranial malignant lesions correlate with the requirement for a long treatment course in postoperative central nervous system infection
}

This article was published in the following Dove Press journal:

Neuropsychiatric Disease and Treatment

4 November 2014

Number of times this article has been viewed

\author{
Heng Zhou \\ Xinghu Zhang \\ Department of Neurology, Beijing \\ Tiantan Hospital, Capital Medical \\ University, Beijing, People's Republic \\ of China
}

\begin{abstract}
Aim: Our aim was to study the clinical features of postoperative meningitis after neurosurgery and identify the factors affecting the duration of treatment.

Methods: This retrospective study assessed 283 patients with postoperative bacterial meningitis in the Neurosurgery Department of Beijing Tiantan Hospital, Beijing, People's Republic of China, between January and December 2012. Patients' clinical data were reviewed, and multivariate logistic regression analysis was used to identify the factors associated with a prolonged treatment course.

Results: The mortality rate was $0.4 \%$ in these patients, of whom $12.4 \%$ were found with pathogens in the cerebrospinal fluid. Among the three most common pathogens detected were methicillin-resistant Staphylococcus aureus, Acinetobacter baumannii, and Pseudomonas aeruginosa. The mean treatment course was $13.5 \pm 2.1$ days. Interestingly, the treatment duration for postoperative meningitis was significantly longer in patients with intracranial malignant tumors than in those with benign lesions. Single-factor analysis showed that male sex $(P=0.042)$ and malignant (rather than benign) lesions $(P<0.001)$ were significantly associated with prolonged treatment duration. Multivariate analysis further confirmed that malignant intracranial lesions represented an independent risk factor for prolonged treatment duration (odds ratio: 2.5962; 95\% confidence interval: 1.1092-6.6134).
\end{abstract}

Conclusion: The nature of the intracranial lesion is an independent risk factor for the duration of treatment in postoperative meningitis after neurosurgery.

Keywords: Acinetobacter baumannii, cerebrospinal fluid, intracranial malignant tumors, methicillin-resistant Staphylococcus aureus, postoperative meningitis, Pseudomonas aeruginosa

\section{Introduction}

In recent years, advances in neuroimaging and surgical interventions have significantly decreased neurosurgical mortality and morbidity. However, postoperative central nervous system infection (PCNSI) remains one of the main reasons for poor prognosis in patients after neurosurgery. Interestingly, the American National Nosocomial Infections Surveillance System assessed a total of 43,135 neurosurgical cases between 1992 and 2004 and found the prevalence of intracranial infection to be about 3\%. Indeed, PCNSI can worsen the underlying disease, delay postoperative recovery of the neurological function, and even cause disability or death. Another study in the People's Republic of China determined the incidence of postoperative intracranial infection after neurosurgery to be between $2.89 \%$ and $5.35 \%{ }^{2}$

Bacterial meningitis represents the main central nervous system infection, and it is associated with relatively high mortality and morbidity. ${ }^{3}$ Postneurosurgical
Correspondence: Xinghu Zhang Department of Neurology, Beijing Tiantan Hospital, Capital Medical University, 6 Tiantan Xili, Dongcheng District, Beijing 100050, People's Republic of China Tel +8613701090674 Fax +86 2I 64085875 Emailxhzhtiantan@hotmail.com 
bacterial meningitis (PNBM) is a potentially life-threatening complication of neurosurgery. ${ }^{4}$ It has been shown to display the highest incidence among all PCNSIs in epidemiological studies. $^{5,6}$ Importantly, bacterial meningitis is one of the most dangerous postneurosurgical complications; $;{ }^{4}$ to some degree, mortality and morbidity due to this infection are affected by the pathological characteristics of the primary lesion, diagnosis time, and administration of specific antimicrobial drugs. ${ }^{7}$ Previous studies have focused mainly on risk factors for PNBM, including the site of the lesion, history of meningitis, surgery that entered a sinus, and increased American Society of Anesthesiologists score, ${ }^{8,9}$ rather than the effects of patients' clinical characteristics on the PNBM treatment course. In this study, we retrospectively analyzed the clinical data of patients who underwent neurosurgery in our hospital in People's Republic of China and carried out a series of statistical analyses to identify the risk factors affecting the duration of the PNBM treatment course, in order to obtain new insights that may prove beneficial for PNBM prevention and treatment.

\section{Materials and methods \\ Patients}

A total of 7,458 patients underwent neurosurgery between January and December 2012 in the Neurosurgery Department of Beijing Tiantan Hospital, Affiliated Hospital of Capital University of Medical Sciences, Beijing, People's Republic of China. Of these patients, 283 (3.8\%) underwent neurosurgery for benign or malignant tumors and were confirmed as having PNBM; there were 158 males (55.8\%) and 125 females (44.2\%) aged $42.7 \pm 7.1$ years (range: $8-74$ years). This study was approved by the Ethics Committee of Beijing Tiantan Hospital, Affiliated Hospital of Capital University of Medical Sciences, Beijing, People's Republic of China. Written informed consent was obtained from each patient included in the study.

\section{Inclusion criteria}

Included in this study were 1) patients who underwent neurosurgery in the Neurosurgery Department of Beijing Tiantan Hospital between January and December 2012 and 2) patients with intracranial infection showing clinical manifestations and auxiliary examination features, including high fever, headache, vomiting, and positive meningeal irritation signs.

Patients with a body temperature of up to $38^{\circ} \mathrm{C}$ were assessed within 24 hours by lumbar puncture; routine blood examinations; bacterial, fungal, and viral cultures of blood and cerebrospinal fluid (CSF); and specific pathogen-antibody titration assays of blood and CSF samples. Intracranial infection was diagnosed based on CSF white blood cell (WBC) count $>100 / \mathrm{mm}^{3}$, neutrophil granulocyte percentage $>80 \%$, CSF glucose $<40 \mathrm{mg} / \mathrm{dL}$, CSF protein $>100 \mathrm{mg} / \mathrm{dL}$, and peripheral WBC count $>10 \times 10^{9} / \mathrm{L} .{ }^{10}$ Regular lumbar punctures and laboratory examinations were carried out during the course of intracranial infection treatment.

\section{Exclusion criteria}

Patients who had 1) incision infections, 2) brain or subdural abscesses, 3) head or spinal injuries, and 4) preoperative fever or elevated peripheral blood WBC count were excluded from this study.

\section{Determination of treatment duration}

The following characteristics were obtained before intracranial infection treatment was decided: 1) normal body temperature, no headaches, no vomiting, and no meningeal irritation signs; 2) normalization of CSF WBC count as well as protein and glucose levels; and 3) normalization of peripheral blood WBC count. Treatment was discontinued with all these criteria met. The treatment duration was defined as the time elapsed between diagnostic confirmation of intracranial infection and treatment termination.

\section{Statistical analysis of the factors associated with prolonged treatment duration}

In order to assess the patient characteristics that were associated with the requirement for prolonged treatment duration of intracranial infection, the 283 patients included in this study (and confirmed as having PNBM) were subdivided into two groups for analysis: patients requiring long-term treatment, defined as $\geq 15$ days, and those requiring short-term treatment, defined as $\leq 14$ days. The use of 14 days as the cutoff point to differentiate between short- and long-term treatments was based on our observation that the mean treatment duration in the 283 patients was $13.5 \pm 2.1$ days and on previous studies of intracranial infections that utilized 14 days to distinguish between treatment durations. ${ }^{11,12}$

Statistical techniques were employed to determine the effects of sex, age, history of hypertension, history of diabetes mellitus, CSF culture, CSF pressure, CSF WBC count, CSF protein content, CSF glucose level, CSF culture results, postoperative drainage, and the nature of the lesion on treatment duration. The data were analyzed using the SPSS 17.0 software (SPSS Inc, Chicago, IL, USA). 
Categorical data were compared using the $\chi^{2}$ test, while intragroup comparisons of continuous data were made using the Student's $t$-test. Initially, one-way analysis of variance was used to identify factors showing significant differences between patient groups. These factors were then subjected to multivariate stepwise logistic regression analysis to determine the independent predictors of prolonged treatment duration. A backward selection method was used to identify variables with a $P$-value $<0.1$ for inclusion into the model, and the standardized regression coefficient was calculated. The treatment duration ( $\leq 14$ days input as $1, \geq 15$ days as 2) was considered the dependent variable, and the risk factors were treated as independent variables. Results were expressed as odds ratios and corresponding $95 \%$ confidence intervals. Differences were considered statistically significant at $P<0.05$.

\section{Results}

\section{Patient characteristics}

Patients' clinical characteristics, CSF culture results, and data obtained by pathological examination of the intracranial lesions are shown in Table 1. Benign tumors were identified in 204 patients and malignant lesions in 79 individuals. The initial clinical manifestations of PNBM included fever, headache, vomiting, decreased consciousness, seizures, and signs of meningeal irritation. Laboratory examinations of CSF obtained by lumbar puncture identified the causative organisms in 35 of the 283 included patients (12.4\%) as methicillin-resistant Staphylococcus aureus, Acinetobacter baumannii, Pseudomonas aeruginosa, Escherichia coli, and Staphylococcus epidermidis.

After PNBM diagnosis, 60 patients were treated with a single antibiotic, while 223 participants received a combination of two or more antibiotics. In patients in whom the causative organism was identified, the antibiotic regimen was adjusted according to the CSF culture results. Successful treatment of intracranial infection was achieved in 282 of the 283 patients, with a treatment duration of $13.5 \pm 2.1$ days. One patient died (a mortality rate of $0.4 \%$ ); subsequent pathologic examinations revealed intracranial metastasis of small cell lung cancer and the cause of death was respiratory failure after the surgery.

\section{Single-factor analysis of characteristics associated with PNBM treatment duration}

To determine which characteristics were associated with PNBM treatment duration, patients were subdivided into two groups that had received treatment for $\geq 15$ days (long treatment) and $\leq 14$ days (short treatment), respectively. This grouping was based on the mean treatment duration of 13.5 \pm 2.1 days obtained for these patients and it was consistent with those in previous studies of bacterial meningitis. ${ }^{11,12}$ As shown in Tables 2 and 3, single-factor analysis revealed significantly higher proportions of males $(P=0.042)$ and patients with malignant lesions $(P<0.001)$

Table I The clinical characteristics of the patients and the results from CSF cultures and pathologic examinations of their intracranial lesions

\begin{tabular}{|c|c|c|c|}
\hline & & Number & $\%$ \\
\hline \multirow[t]{2}{*}{ Sex } & Male & 158 & 55.8 \\
\hline & Female & 125 & 44.2 \\
\hline \multirow[t]{4}{*}{ Age (years) } & $<20$ & 66 & 23.3 \\
\hline & $21-40$ & 96 & 33.9 \\
\hline & $4 I-60$ & 93 & 32.9 \\
\hline & $>60$ & 28 & 9.9 \\
\hline Initial & Fever & $27 \mid$ & 95.8 \\
\hline \multirow[t]{5}{*}{ symptoms } & Headache & 216 & 76.3 \\
\hline & Meningeal irritation & 277 & 97.9 \\
\hline & Vomiting & 93 & 32.9 \\
\hline & Lowering of consciousness & 45 & 15.9 \\
\hline & Seizures & 26 & 9.2 \\
\hline \multirow[t]{5}{*}{$\begin{array}{l}\text { CSF culture } \\
\text { results }\end{array}$} & $\begin{array}{l}\text { Methicillin-resistant Staphylococcus } \\
\text { aureus }\end{array}$ & 10 & 28.6 \\
\hline & Acinetobacter baumannii & 8 & 22.9 \\
\hline & Pseudomonas aeruginosa & 6 & I7. \\
\hline & Escherichia coli & 6 & I7. \\
\hline & Staphylococcus epidermidis & 5 & 14.3 \\
\hline Benign & Meningioma & 36 & \\
\hline \multirow[t]{12}{*}{ lesions } & Cavernous hemangioma & 9 & \\
\hline & Spinal meningioma & 19 & \\
\hline & Craniopharyngioma & 41 & \\
\hline & Cerebrovascular malformation & 18 & \\
\hline & Hypophysoma & 12 & \\
\hline & Schwannoma & 31 & \\
\hline & Benign ependymoma & 10 & 6.1 \\
\hline & Teratoma & 5 & \\
\hline & CNS epidermoid cyst & 15 & \\
\hline & $\begin{array}{l}\text { CNS inflammatory demyelinating } \\
\text { disease }\end{array}$ & 2 & \\
\hline & Arachnoid cyst & 4 & \\
\hline & CNS inflammatory granuloma & 2 & \\
\hline Malignant & Astrocytoma & 21 & \\
\hline \multirow[t]{9}{*}{ lesions } & Spongioblastoma & 16 & \\
\hline & Medulloblastoma & 8 & \\
\hline & Malignant ependymoma & 5 & \\
\hline & Oligodendroglioma & 7 & \\
\hline & Papilloma of choroid plexus & 5 & \\
\hline & Pineoblastoma & 6 & \\
\hline & Hemangioblastoma & 7 & \\
\hline & Malignant melanoma & 2 & \\
\hline & Metastatic carcinoma & 2 & \\
\hline
\end{tabular}

Abbreviations: CSF, cerebrospinal fluid; CNS, central nervous system. 
Table 2 Single-factor analysis of the variables affecting treatment duration: categorical data

\begin{tabular}{|c|c|c|c|c|c|}
\hline & Total, n (\%) & $\begin{array}{l}\text { Treatment } \\
\geq 15 \text { days, } \mathbf{n}(\%)\end{array}$ & $\begin{array}{l}\text { Treatment } \\
\leq 14 \text { days, } n(\%)\end{array}$ & $\chi^{2}$ value & $P$-value \\
\hline Total & $283(100)$ & $7 I(25.1)$ & $212(74.9)$ & & \\
\hline \multicolumn{6}{|l|}{ Sex } \\
\hline Male & I 58 (55.8) & $47(66.2)$ & III (52.4) & 0.815 & 0.042 \\
\hline Female & $125(44.2)$ & $24(33.8)$ & 101 (47.6) & & \\
\hline \multicolumn{6}{|l|}{ Hypertension } \\
\hline Yes & $6(2.1)$ & $2(2.8)$ & $4(1.9)$ & 2.633 & 0.607 \\
\hline No & 277 (97.9) & $69(97.2)$ & $208(98.1)$ & & \\
\hline \multicolumn{6}{|l|}{ Diabetes } \\
\hline Yes & $8(2.8)$ & $4(5.6)$ & $4(1.9)$ & 4.182 & 0.588 \\
\hline No & $275(97.2)$ & $67(94.4)$ & $208(98.1)$ & & \\
\hline \multicolumn{6}{|l|}{ CSF culture } \\
\hline Positive & $35(12.4)$ & $5(7.0)$ & $30(14.2)$ & 1.019 & 0.082 \\
\hline Negative & $248(87.6)$ & $66(93.0)$ & I82 (85.8) & & \\
\hline \multicolumn{6}{|c|}{ Postoperative drainage } \\
\hline Yes & $63(22.3)$ & I5 (2I.I) & $48(22.6)$ & 1.443 & 0.791 \\
\hline No & $220(77.7)$ & $56(78.9)$ & $164(77.4)$ & & \\
\hline \multicolumn{6}{|c|}{ Lumbar cistern drainage } \\
\hline Yes & $72(25.4)$ & $20(28.2)$ & $52(24.5)$ & 1.287 & 0.544 \\
\hline No & $211(74.6)$ & $5 I(7 \mid .8)$ & $160(75.5)$ & & \\
\hline \multicolumn{6}{|c|}{ Lesion nature } \\
\hline Benign & $205(72.4)$ & $37(52.1)$ & $168(79.2)$ & 3.420 & $<0.001$ \\
\hline Malignant & $78(27.6)$ & 34 (47.9) & $44(20.8)$ & & \\
\hline
\end{tabular}

Abbreviation: CSF, cerebrospinal fluid.

in the long-term treatment group compared with those who received short-term treatment. However, age, history of hypertension, history of diabetes, CSF culture, CSF pressure, CSF WBC count, CSF protein content, CSF glucose level, postoperative drainage, and lumbar cistern drainage were not significantly different between both groups.

\section{Multivariate logistic regression analysis of the factors associated with PNBM treatment duration}

Patient sex, the nature of the lesion (benign or malignant), CSF pressure, and CSF culture were selected as independent variables for the multivariate logistic regression analysis. As shown in Table 4, the nature of the lesion constituted the risk factor significantly affecting the treatment duration (odds ratio: $2.5962,95 \%$ confidence interval: 1.1092-6.6134), with the presence of malignant lesions requiring a long treatment course.

\section{Discussion}

The following main findings were obtained in this analysis: methicillin-resistant $S$. aureus, A. baumannii, and $P$. aeruginosa were the three most common pathogens identified in CSF cultures from patients with PNBM; the group of patients treated for $\geq 15$ days contained more males and showed higher incidence of malignant lesions compared with the short-term treatment group; the presence of a malignant lesion was an independent predictor of the requirement for a long-term treatment course ( $\geq 15$ days) in PNBM. Thus, clinicians should be aware that postneurosurgery,

Table 3 Single-factor analysis of the variables affecting treatment duration: continuous data

\begin{tabular}{|c|c|c|c|c|}
\hline & Treatment $\geq 15$ days & Treatment $\leq 14$ days & $t$-value & $P$-value \\
\hline Total, n (\%) & 7I (25.I) & $212(74.9)$ & & \\
\hline Age (years) & $43.1 \pm 6.2$ & $42.0 \pm 5.9$ & 0.984 & 0.790 \\
\hline CSF pressure $(\mathrm{mmHg})$ & $204.6 \pm 18.5$ & $217.0 \pm 20.1$ & 1.016 & 0.055 \\
\hline CSF white cell count $\left(/ \mathrm{mm}^{3}\right)$ & $511.4 \pm 42.6$ & $498.5 \pm 54.2$ & 0.843 & 0.372 \\
\hline CSF protein content $(\mathrm{mg} / \mathrm{dL})$ & $207.1 \pm 25.3$ & $223.6 \pm 27.2$ & 0.902 & 0.213 \\
\hline CSF glucose content (mg/dL) & $33.5 \pm 5.0$ & $34.8 \pm 4.7$ & 0.882 & 0.237 \\
\hline
\end{tabular}

Note: Data are presented as the mean \pm standard deviation, unless otherwise indicated. Abbreviation: CSF, cerebrospinal fluid. 
Table 4 Logistic regression analysis of the variables affecting treatment duration

\begin{tabular}{lll}
\hline & Odds ratio & 95\% confidence interval \\
\hline Sex & 0.7140 & $0.2438-16.0844$ \\
Lesion nature & 2.5962 & $1.1092-6.6134$ \\
CSF culture & 0.8825 & $0.5238-27.3126$ \\
CSF pressure $(\mathrm{mmHg})$ & 0.6375 & $0.3116-36.4973$ \\
\hline
\end{tabular}

Abbreviation: CSF, cerebrospinal fluid.

intracranial infections in patients with malignant lesions may require longer duration of antibiotic therapy.

CSF culture is considered the gold standard for the diagnosis of bacterial meningitis. ${ }^{3}$ According to a study by Pizon et $\mathrm{al}^{13} \mathrm{CSF}$ staining and culture provide the diagnostic basis in $60 \%-90 \%$ of patients with meningitis. Previous studies have shown that prophylactic use of antibiotics can effectively reduce the incidence of PCNSI. ${ }^{14,15}$ However, such prophylaxis will also decrease the rate of successful growth and identification of organisms in blood and CSF cultures. ${ }^{16}$ All the patients assessed herein received antibiotic prophylaxis prior to surgery, which likely explains the low rate of organism growth in CSF cultures (12.4\%). Hence, in situations where antibiotic prophylaxis is used, other indices can help in diagnosing bacterial meningitis, including CSF glucose level, lactate content, and cell classification. ${ }^{17}$ In addition, $99 \%$ of patients with PNBM show clinical manifestations such as headache, fever, signs of meningeal irritation, and decreased consciousness. ${ }^{18}$ Therefore, the patient's clinical symptoms and signs, combined with laboratory results, provide sufficient evidence for the diagnosis of bacterial meningitis. ${ }^{19}$

PNBM differs from community-acquired bacterial meningitis in terms of the susceptible population and pathogen characteristics. ${ }^{20,21} \mathrm{We}$ have shown herein that methicillinresistant $S$. aureus, $A$. baumannii, and $P$. aeruginosa are the three most common strains in CSF cultures, consistent with previous findings. ${ }^{22}$ For patients with negative CSF culture results, the antibiotic regimen selection for empirical therapy should be done in accordance with the epidemiological characteristics of the pathogens. Therefore, cefazolin, ceftriaxone, or meropenem, combined with vancomycin or linezolid, would be expected to effectively cover the common bacterial spectrum of PNBM.

The patients assessed herein were closely monitored after surgery for signs of fever, decreased consciousness, or meningeal irritation. Any patient suspected with PNBM was assessed within 24 hours by lumbar puncture and laboratory tests, which included CSF cytology, biochemistry, staining, culture, and antibody assays. Once the diagnosis was confirmed, antibiotic therapy was commenced immediately. Patients in whom the causative organism could not be identified were treated with empirical antibiotic therapy, according to clinicians' experience and relevant research data. ${ }^{23}$ The treatment options included single-antibiotic (third-generation cephalosporin or meropenem) or combination therapy (thirdgeneration cephalosporin or meropenem combined with vancomycin). During the course of treatment, the regimen was adjusted according to the etiology (ie, identification of the causative organism). Several studies have shown that early diagnosis and treatment can significantly improve the prognosis of bacterial meningitis. ${ }^{24,25}$ The clinicians involved in this study were fully aware that bacterial meningitis is an important potential postoperative complication and that once PNBM is diagnosed, antibiotic therapy should be administered as soon as possible; this would have effectively improved the prognosis of the patients in this study. ${ }^{26}$ This may also explain the low mortality rate observed (only one patient died, due to respiratory insufficiency).

The average duration of treatment in this study was $13.5 \pm 2.1$ days, comparable to values reported previously in similar studies involving bacterial meningitis. ${ }^{11,12}$ Therefore, we selected 14 days as the cutoff point and subdivided the patients into two groups, one composed of patients treated beyond average duration ( $\geq 15$ days), and the other made up of individuals treated with average duration or less ( $\leq 14$ days). Our statistical analyses revealed that the treatment duration required in patients with PNBM was longer in those with intracerebral malignant lesions compared with individuals having benign lesions. A possible explanation is that there may be differences in postoperative immune states between patients with malignancies and those with benign lesions. Studies of postoperative immune function in patients with meningioma or glioma have demonstrated that all patients show immunosuppression after neurosurgery; however, although the immune function of patients with benign lesions began to recover 2-3 days after surgery (characterized as increased lymphocyte activity), patients with malignant lesions exhibited postoperative immunosuppression for 7-10 days. ${ }^{27}$ In addition, lymphocyte activity was significantly lower after surgery compared with the preoperative period, despite a notably increased count. ${ }^{28} \mathrm{~T}$-helper cell and eosinophil levels were found to be lower in patients with intracranial malignant tumors (World Health Organization grade II-IV glioma) than in those with benign lesions, while immunoglobulin (Ig) M and neutrophil levels were higher. ${ }^{29}$ Previous studies have also reported that postoperative serum 
IgA and IgG levels were significantly reduced in patients with intracranial malignant tumors. ${ }^{30}$ Thus, the requirement for a long duration of PNBM treatment observed in patients with malignant tumors may be secondary to the malignancy's immunosuppressive effects.

Immunosuppression in patients with intracranial malignant tumors may be related to increased levels of cytokines with immunosuppressive function, including interleukin-10 and transforming growth factor- $\beta 1$, along with decreased interleukin-12 level. ${ }^{31,32}$ The secretion of prostaglandin E2 is increased in patients with intracranial malignant tumors, possibly mediating the inhibitory effects of monocytes and macrophages on T-cells. In addition, the activity of immune cells passing through the blood-brain barrier may also be reduced by tumor cells, further suppressing the immune function in patients with malignant intracranial lesions. ${ }^{33}$ Interestingly, studies at the molecular level have suggested that the postoperative immune function of patients with glioma was significantly lower in those whose tumors retained chromosome $10 \mathrm{q}$ than in individuals with allelic $10 \mathrm{q}$ loss; importantly, patients without 10q allelic loss were also more likely to have postoperative infection. ${ }^{34}$

The present study has described the common pathogens associated with PNBM, outcomes, and factors associated with treatment duration; these findings may prove beneficial for disease prevention and treatment. Several studies have reported the clinical characteristics of PNBM. ${ }^{35,36}$ However, we assessed a larger sample size (283 cases), systematically investigated the characteristics of postneurosurgery meningitis, and analyzed the factors affecting the duration of treatment. In addition, this study was carried out in a Chinese population, in mainland People's Republic of China; to our knowledge, no previous reports exist on clinical characteristics and treatment of PNBM in a Chinese population, although a few studies in Taiwanese patients have been published. ${ }^{35,36}$ Furthermore, we found for the first time that intracranial malignant lesions represent an independent risk factor for prolonged treatment duration.

\section{Conclusion}

PNBM is an important complication of neurosurgery, but the prophylactic use of antibiotics decreases the rate of positive CSF cultures in patients with intracranial infections. Therefore, PNBM diagnosis requires a comprehensive consideration of the signs, symptoms, and results from laboratory tests of the CSF. Furthermore, intracranial malignant lesions represent an independent risk factor for the prognosis of PNBM treatment.

\section{Disclosure}

The authors report no conflicts of interest in this work.

\section{References}

1. National Nosocomial Infections Surveillance System. National Nosocomial Infections Surveillance (NNIS) System Report, data summary from January 1992 through June 2004, issued October 2004. Am J Infect Control. 2004;32(8):470-485.

2. Xu G, Zhang F, Chen QX. [Analysis of high risk factors correlated to the associated intracranial infection postcraniotomy]. Chin J Clin NeuroSurg. 2008;13(6):362-364. Chinese.

3. Brouwer MC, Tunkel AR, van de Beek D. Epidemiology, diagnosis, and antimicrobial treatment of acute bacterial meningitis. Clin Microbiol Rev. 2010;23(3):467-492.

4. Srinivas D, Veena Kumari HB, Somanna S, Bhagavatula I, Anandappa CB. The incidence of postoperative meningitis in neurosurgery: an institutional experience. Neurol India. 2011;59(2):195-198.

5. Federico G, Tumbarello M, Spanu T, et al. Risk factors and prognostic indicators of bacterial meningitis in a cohort of 3580 postneurosurgical patients. Scand J Infect Dis. 2001;33(7):533-537.

6. Korinek AM, Baugnon T, Golmard JL, van Effenterre R, Coriat P, Puybasset L. Risk factors for adult nosocomial meningitis after craniotomy: role of antibiotic prophylaxis. Neurosurgery. 2006;59(1): 126-133; discussion 126-133.

7. Wang KW, Chang WN, Huang CR, et al. Post-neurosurgical nosocomial bacterial meningitis in adults: microbiology, clinical features, and outcomes. J Clin Neurosci. 2005;12(6):647-650.

8. Yang ZJ, Zhong HL, Wang ZM, Zhao F, Liu PN. Prevention of postoperative intracranial infection in patients with cerebrospinal fluid rhinorrhea. Chin Med J (Engl). 2011;124(24):4189-4192.

9. Kourbeti IS, Jacobs AV, Koslow M, Karabetsos D, Holzman RS. Risk factors associated with postcraniotomy meningitis. Neurosurgery. 2007;60(2):317-325; discussion 325-326.

10. World Health Organisation. Vaccine Research and Development Generic Protocol for Population-Based Surveillance of Haemophilus influenzae Type B. Geneva: WHO; 1996.

11. Mobarak EI. Trend, features and outcome of meningitis in the Communicable Diseases hospital, Alexandria, Egypt, 1997-2006. J Egypt Public Health Assoc. 2012;87(1-2):16-23.

12. Lazzarini L, Toti M, Fabris $P$, Mentore Study Group Clinical Investigators, et al. Clinical features of bacterial meningitis in Italy: a multicenter prospective observational study. J Chemother. 2008;20(4):478-487.

13. Pizon AF, Bonner MR, Wang HE, Kaplan RM. Ten years of clinical experience with adult meningitis at an urban academic medical center. J Emerg Med. 2006;30(4):367-370.

14. Barker FG 2nd. Efficacy of prophylactic antibiotics against meningitis after craniotomy: a meta-analysis. Neurosurgery. 2007;60(5):887-894; discussion 887-894.

15. Moorthy RK, Sarkar H, Rajshekhar V. Conservative antibiotic policy in patients undergoing non-trauma cranial surgery does not result in higher rates of postoperative meningitis: an audit of nine years of narrow-spectrum prophylaxis. Br J Neurosurg. 2013;27(4):497-502.

16. Sharma MS, Vohra A, Thomas P, et al. Effect of risk-stratified, protocolbased perioperative chemoprophylaxis on nosocomial infection rates in a series of 31927 consecutive neurosurgical procedures (1994-2006). Neurosurgery. 2009;64(6):1123-1130; discussion 1130-1131.

17. Tavares WM, Machado AG, Matushita H, Plese JP. CSF markers for diagnosis of bacterial meningitis in neurosurgical postoperative patients. Arq Neuropsiquiatr. 2006;64(3A):592-595.

18. van de Beek D, de Gans J, Spanjaard L, Weisfelt M, Reitsma JB, Vermeulen M. Clinical features and prognostic factors in adults with bacterial meningitis. N Engl J Med. 2004;351(18):1849-1859.

19. Dzupova O, Polivkova S, Smiskova D, Benes J. [Epidemiological, clinical and laboratory characteristics of bacterial meningitis in adult patients]. Klin Mikrobiol Infekc Lek. 2010;16(2):58-63. Czech. 
20. Weisfelt M, van de Beek D, Spanjaard L, de Gans J. Nosocomial bacterial meningitis in adults: a prospective series of 50 cases. J Hosp Infect. 2007;66(1):71-78.

21. Chang WN, Lu CH, Huang CR, et al. Changing epidemiology of adult bacterial meningitis in southern taiwan: a hospital-based study. Infection. 2008;36(1):15-22.

22. Streharova A, Benca J, Holeckova K, et al. Comparison of postsurgical and community acquired bacterial meningitis - analysis of 372 cases within a nationwide survey. Neuro Endocrinol Lett. 2007; 28(suppl 3):7-9.

23. Lu CH, Chang WN, Chang HW. Klebsiella meningitis in adults: clinical features, prognostic factors and therapeutic outcomes. J Clin Neurosci. 2002;9(5):533-538.

24. Koster-Rasmussen R, Korshin A, Meyer CN. Antibiotic treatment delay and outcome in acute bacterial meningitis. J Infect. 2008;57(6): 449-454.

25. Lepur D, Barsic B. Community-acquired bacterial meningitis in adults: antibiotic timing in disease course and outcome. Infection 2007;35(4):225-231.

26. Dzupova O, Rozsypal H, Prochazka B, Benes J. Acute bacterial meningitis in adults: predictors of outcome. Scand J Infect Dis. 2009; 41(5):348-354.

27. Lisianyi NI, Romodanov SA, Trosh RM, Rudenko VA, Radzievskii AA. [Changes in the immune status of patients with brain tumors in the pre- and postoperative periods]. Zh Vopr Neirokhir Im N N Burdenko. 1991;4:19-21. Russian.

28. Lisianyi NI, Romodanov SA, Rudenko VA, Trosh RM, Radzievskii AA, Sosnov Iu D. [The effect of surgical intervention on the state of the immune system in brain tumors]. Klin Khir. 1990;12:4-6. Russian.
29. Dauch WA, Krex D, Heymanns J, Zeithammer B, Bauer BL. Peri-operative changes of cellular and humoral components of immunity with brain tumour surgery. Acta Neurochir (Wien). 1994;126(2-4):93-101.

30. Kempuraj D, Devi RS, Madhappan B, et al. T lymphocyte subsets and immunoglobulins in intracranial tumor patients before and after treatment, and based on histological type of tumors. Int J Immunopathol Pharmacol. 2004;17(1):57-64.

31. Sablotzki A, Ebel H, Mühling J, et al. Dysregulation of immune response following neurosurgical operations. Acta Anaesthesiol Scand. 2000;44(1):82-87.

32. Kumar R, Kamdar D, Madden L, et al. Th1/Th2 cytokine imbalance in meningioma, anaplastic astrocytoma and glioblastoma multiforme patients. Oncol Rep. 2006;15(6):1513-1516.

33. Khonina NA, Tsentner MI, Leplina OIu, et al. [Characteristics and immunologic changes in patients with malignant brain tumors]. Vopr Onkol. 2002;48(2):196-201. Russian.

34. Aghi MK, Batchelor TT, Louis DN, Barker FG 2nd, Curry WT Jr. Decreased rate of infection in glioblastoma patients with allelic loss of chromosome 10q. J Neurooncol. 2009;93(1):115-120.

35. Huang $\mathrm{CR}$, Chen SF, Lu CH, et al. Clinical characteristics and therapeutic outcomes of nosocomial super-infection in adult bacterial meningitis. BMC Infect Dis. 2011;11:133.

36. Chang WN, Lu CH, Huang CR, et al. Clinical characteristics of postneurosurgical Klebsiella pneumoniae meningitis in adults and a clinical comparison to the spontaneous form in a Taiwanese population. J Clin Neurosci. 2010;17(3):334-338.
Neuropsychiatric Disease and Treatment

\section{Publish your work in this journal}

Neuropsychiatric Disease and Treatment is an international, peerreviewed journal of clinical therapeutics and pharmacology focusing on concise rapid reporting of clinical or pre-clinical studies on a range of neuropsychiatric and neurological disorders. This journal is indexed on PubMed Central, the 'PsycINFO' database and CAS,

\section{Dovepress}

and is the official journal of The International Neuropsychiatric Association (INA). The manuscript management system is completely online and includes a very quick and fair peer-review system, which is all easy to use. Visit http://www.dovepress.com/testimonials.php to read real quotes from published authors. 